\title{
A Regiospecific Monooxygenase with Novel Stereopreference Is the Major Pathway for Arachidonic Acid Oxygenation in Isolated Epidermal Cells
}

\author{
Michael J. Holtzman, John Turk, * and Alice Pentland \\ Departments of Medicine and ${ }^{*}$ Pathology, Washington University School of Medicine, St. Louis, Missouri 63110
}

\begin{abstract}
We investigated the enzymatic mechanisms responsible for AA oxygenation in homogenous cell suspensions obtained by trypsinization of epidermis from healthy subjects. Cell incubation with $\mathrm{AA}(0.3-150 \mu \mathrm{M})$ invariably resulted in the predominant generation of a compound identified as 12-hydroxyeicosatetraenoic acid (12-HETE) by HPLC and by both negative-ion chemical ionization and electron-impact mass spectrometry. Maximal amounts of $12-\mathrm{HETE}$ were $126 \pm 21 \mathrm{pmol} / 10^{6}$ cells $( \pm \mathrm{SE})$, and concentration-response curves yielded half-maximal levels for 12-HETE similar to $\mathrm{PGE}_{2}$ at $2 \mu \mathrm{M}$ AA. Two epoxyeicosatrienoic acids derived from AA were also identified. Stereochemical analysis by chiral-phase chromatography demonstrated that the epidermal cell 12-HETE was a mixture of the $12 S$ - and $12 R$-hydroxy isomers in a molar ratio varying from 2:1 to 8:1 among subjects. Subcellular fractionation into $12,000 \mathrm{~g}$ pellet (containing mitochondria) and $100,000 \mathrm{~g}$ supernatant (cytosol) and pellet (microsome) demonstrated that $>99 \%$ of the 12-HETE was generated by enzymatic activity distributed equally in the two pellets. Both mitochondrial and microsomal activities were increased upon addition of NADPH and were inhibited by carbon monoxide, but the molar ratio of $12 S / 12 R-H E T E$ was threefold greater in microsomal than in mitochondrial fractions. The results demonstrate that human epidermis contains active membrane-bound monooxygenase(s) which preferentially generates 12-HETE from AA, exhibits a $12 S$ stereopreference of hydroxylation, and suggests the presence of distinct mitochondrial and microsomal enzyme systems in epidermal cells.
\end{abstract}

\section{Introduction}

The potential involvement of oxygenation products of AA in the development of inflammatory skin diseases, particularly psoriasis, has been the subject of a variety of recent studies. Approaches to understanding the pathophysiological basis of altered arachidonate metabolism have included determining the effects of intradermal or topical administration of arachidonate metabolites and assaying the levels of such compounds in biological specimens, including biopsies from the epidermis of patients with psoriasis. Results of such studies indicate that:

Address correspondence to Dr. Holtzman, Washington University School of Medicine, 660 S. Euclid Avenue, Box 8052, St. Louis, MO 63110.

1989.

Received for publication 24 May 1989 and in revised form 20 July

J. Clin. Invest.

(c) The American Society for Clinical Investigation, Inc.

$0021-9738 / 89 / 11 / 1446 / 08 \quad \$ 2.00$

Volume 84, November 1989, 1446-1453 (a) concentrations of $\mathrm{AA}, 12-$ hydroxyeicosatetraenoic acid (12-HETE), ${ }^{1}$ PG, and leukotrienes are increased in psoriatic lesional epidermis (1-4); $(b)$ whole human epidermis from healthy or diseased skin has the enzymatic capacity to convert AA to some of these same compounds (1-6); and (c) topical or intradermal administration of 12-HETE or leukotrienes may cause epidermal inflammation and proliferation $(7,8)$.

The precise enzymatic mechanisms responsible for the generation of the major arachidonate product 12-HETE by epidermis and the localization of the enzyme(s) to the epidermal cells have not been established. Dermal elements such as fibroblasts, as well as inflammatory cells, are often included in dermatome preparations of human skin, and the enzymatic pathways leading to HETE formation' in the skin have only been assumed to represent the activity of an arachidonate lipoxygenase. The recent observation that the 12-HETE in psoriatic lesions is not the expected lipoxygenase-derived $12 S$-hydroxy enantiomer but instead may consist predominantly of the $12 R$-isomer (9) suggests that an enzyme other than the 12-lipoxygenase may be activated in inflamed epidermis. For example, cytochrome P-450 monooxygenases have been reported to produce predominantly $12 R$-rather than $12 S$-HETE from arachidonate in hepatic tissue (10).

The present experiments were designed to define the arachidonate oxygenation pathways contained in isolated human epidermal cell suspensions purified from healthy skin. To our knowledge this is the first comprehensive report of arachidonate products from intact, freshly isolated human epidermal cells. The predominant pathway for arachidonate oxygenation was found to be a novel enzyme system that selectively converts AA to 12-HETE and exhibits the properties of a membrane-bound cytochrome P-450 monooxygenase. This enzymatic activity demonstrates features distinct from those of hepatic and renal microsomal P-450 systems in animals and humans (10-12).

\section{Methods}

Materials. $\left[1-{ }^{14} \mathrm{C}\right] \mathrm{AA}(55 \mathrm{mCi} / \mathrm{mmol}),\left[{ }^{3} \mathrm{H}_{8}\right] \mathrm{AA}(95 \mathrm{Ci} / \mathrm{mmol})$, and $\left[1-{ }^{14} \mathrm{C}\right]$ linoleic acid $(51 \mathrm{mCi} / \mathrm{mmol})$ were from New England Nuclear (Boston, MA); unlabeled AA was from Nu Check Prep, Inc. (Elysian, MN); NADPH (tetrasodium salt type I), NADP (monosodium salt), NAD (grade III), glucose-6-phosphate (G-6-P), G-6-P dehydrogenase (G-6-PD), and protease inhibitors were purchased from Sigma Chemical Co. (St. Louis, MO); carbon monoxide (99\%) and nitrogen were from Matheson (Secaucus, NJ); derivatizing reagents were from Pierce Chemical Co. (Rockford, IL) and Matheson, Coleman, and Bell

1. Abbreviations used in this paper: EET, epoxyeicosatrienoic acid; EI, electron impact; GC, gas chromatography; G-6-P, glucose-6-phosphate; G-6-PD, G-6-P dehydrogenase; HETE, hydroxyeicosatetraenoic acid; HODE, hydroxyoctadecadienoic acid; MS, mass spectrometry; NICI, negative-ion chemical ionization; PFBE, pentafluorobenzyl ester; TMSE, trimethylsilyl ether. 
(Norwood, OH); organic solvents were from Burdick \& Jackson Laboratories Inc. (Muskegon, MI); and HBSS containing Hepes ( $25 \mathrm{mM}$ ), and DME containing $5 \%$ FCS and fungizone were from the University Tissue Culture Support Center.

Authentic reference compounds included (12S)- and (12R)-hydroxy-(5Z,8Z,10E,14Z)-eicosatetraenoic acid (12S- and $12 R$-HETE), (15S)-hydroxy-(5Z,8Z,11Z,13E)-eicosatetraenoic acid (15S-HETE), (5)-hydroxy-(6E,8Z,11Z,14Z)-eicosatetraenoic acid (5-HETE), (5,6)-, $(8,9)-,(11,12)-$, and $(14,15)$-epoxyeicosatrienoic acids $(5,6-, 8,9-$, $11,12-$, and 14,15-EETs), and 13-hydroxy-(9Z,11E)-octadecadienoic acid (13-HODE) obtained from Biomol Research Laboratories Inc. (Plymouth Meeting, PA) and Cayman Chemical Co., Inc. (Ann Arbor, $\mathrm{MI}$ ); and $\mathrm{PGE}_{2}, \mathrm{PGF}_{2 \alpha}, \mathrm{PGD}_{2}$, and $\mathrm{PGB}_{2}$ from Sigma Chemical Co.

Cell isolation. Epidermal cells were purified from otherwise healthy human skin obtained at surgery for panniculectomy or breast reduction or from neonatal foreskin. Cells prepared from all three sources exhibited similar generation of metabolites, so no attempt was made to report data from each source separately. Skin was rinsed in DME containing $2 \mu \mathrm{g} / \mathrm{ml}$ fungizone, then stripped of the deep dermis and fat and placed in $0.25 \%$ trypsin in PBS for $18 \mathrm{~h}$. The epidermis was lifted off, placed into DME containing 5\% FCS, and triturated to create an even cell suspension. Preparations stained with a modified Wright's stain revealed $<0.1 \%$ granulocytes.

Cell incubation conditions. Cellular capacity for oxygenation of exogenous substrate was tested by adding replicate aliquots of cells resuspended in Hepes-buffered HBSS (pH 7.4) to equal volumes of media containing AA dissolved in ethanol. Final concentrations of 2.5 $\times 10^{6}$ cells $/ \mathrm{ml}, 0.03-150 \mu \mathrm{M}$ unlabeled AA, $2-4 \times 10^{6} \mathrm{dpm} / \mathrm{ml}\left[{ }^{3} \mathrm{H}\right]-$ or $\left[{ }^{14} \mathrm{C}\right] \mathrm{AA}$, and $0.5 \%$ ethanol were tested for $1-45 \mathrm{~min}$ at $37^{\circ} \mathrm{C}$ to arrive at conditions for maximal product generation. Identical conditions were used to test oxygenation of $\left[{ }^{14} \mathrm{C}\right]$ linoleic acid. Reagents incubated with boiled cells $\left(100^{\circ} \mathrm{C}\right.$ for $\left.15 \mathrm{~min}\right)$ or cell-free media demonstrated insignificant generation of metabolites.

Subcellular fractionation. AA oxygenation was also studied in mitochondrial, cytosolic, and microsomal fractions obtained after disruption of cells by sonication and separation of subcellular fractions by differential centrifugation at $4^{\circ} \mathrm{C}$. Cell suspensions $\left(1-2 \times 10^{8}\right.$ cells $/ \mathrm{ml}$ ) were sonicated at the microtip limit for $200 \mathrm{~s}$ ( 20 cycles of $10 \mathrm{~s}$ each) in $50 \mathrm{mM}$ Tris- $\mathrm{HCl}$ (pH 7.4) containing $1 \mathrm{mM}$ EDTA, $1 \mathrm{mM}$ EGTA, and a mixture of protease inhibitors $(10 \mu \mathrm{M}$ chymostatin, pepstatin $A$, and leupeptin, and $1 \mathrm{mM}$ sodium metabisulfite and PMSF). Assay of sonicated mixtures demonstrated no loss of oxygenation activity compared with intact cells. The mixtures were centrifuged at $400 \mathrm{~g}$ for $10 \mathrm{~min}$, and the resulting supernatants centrifuged at $12,000 \mathrm{~g}$ for $20 \mathrm{~min}$ and then $100,000 \mathrm{~g}$ for $1 \mathrm{~h}$. In some experiments pellets obtained at 12,000 and $100,000 \mathrm{~g}$ were resuspended with a tissue homogenizer and recentrifuged. Electron microscopy demonstrated that mitochondria were confined to the $12,000 \mathrm{~g}$ pellet and that the $100,000 \mathrm{~g}$ pellet contained only microsomal membrane. Protein in each fraction was determined by the Bradford method using BSA as a standard (Bio-Rad Laboratories, Richmond, CA).

Oxygenase assay conditions. The pellets obtained by centrifugation at 12,000 and at $100,000 \mathrm{~g}$ were resuspended in $50 \mathrm{mM}$ Tris- $\mathrm{HCl}(\mathrm{pH}$ 7.4) with $1 \mathrm{mM}$ EDTA, $1 \mathrm{mM}$ EGTA, and $5 \%$ glycerol for assay of oxygenation activity, and the supernatants from $100,000 \mathrm{~g}$ were assayed directly. Incubations were carried out at $37^{\circ} \mathrm{C}$ for $30 \mathrm{~min}$ after addition of $20-40 \mu \mathrm{M}\left[{ }^{14} \mathrm{C}\right] \mathrm{AA}$. Oxygenation activity was compared with activity generated after the addition of a system to produce reducing equivalents $(10 \mathrm{mM} \mathrm{MgCl}, 0.4 \mathrm{mM} \mathrm{G}-6-P, 1 \mathrm{U} / \mathrm{ml} \mathrm{G}-6-\mathrm{PD}$, and $1 \mathrm{mM}$ NADPH), and with activity after addition of a system to compete with reducing equivalents ( $1 \mathrm{mM}$ NADP and $1 \mathrm{mM}$ NAD). All fractions were also tested with or without the addition of $5 \mathrm{mM}$ $\mathrm{CaCl}_{2}$.

In addition, maximal activity was compared with activity generated under the same conditions except that the buffer also contained carbon monoxide. Buffer gassed with an equivalent amount of nitrogen served as a control. Reagent-containing buffers saturated with carbon monoxide or nitrogen were added to the 12,000 or $100,000 \mathrm{~g}$ pellets resuspended in air-saturated buffer, and standard solubility coefficients in water were used to calculate molar gas ratios.

Preparation of arachidonate 12-lipoxygenase. To compare the procedures for subcellular fractionation, carbon monoxide treatment, and determination of product stereochemistry on an authentic arachidonate 12-lipoxygenase, parallel experiments were carried out on the arachidonate 12-lipoxygenase isolated from epithelial cells obtained from bovine trachea $(13,14)$. Procedures were identical to those for isolation of the epidermal cell enzyme noted above and for product characterization as noted below.

Extraction of oxygenation products. Incubations were stopped by rapid cooling to $4^{\circ} \mathrm{C}$, and an aliquot of $\mathrm{PGB}_{2}$ was added to serve as an internal standard for product recovery. In some experiments trimethylphosphite was added to reduce possible hydroperoxides to alcohols. Cell supernatants or enzyme mixtures were extracted with 2-propanol/chloroform/acetic acid or with diethylether/acetic acid as described previously $(15,16)$. Recoveries of $\mathrm{PGB}_{2}$ and other $\mathrm{PG}$ and mono- and dihydroxylated derivatives of $A A$ were similar $(75 \pm 3 \%$, mean \pm SE).

HPLC. Extracts were reconstituted in chromatographic solvent and analyzed by reverse-phase, straight-phase, and chiral-phase HPLC on a liquid chromatograph (model 1090M; Hewlett-Packard Co., Palo Alto, CA). For reverse-phase HPLC the chromatograph was fitted with a guard cartridge and a $4.6 \times 100-\mathrm{mm}$ analytical column packed with 3 $\mu \mathrm{m}$ octadecylsilane-coated particles (Dynamax; Rainin Instrument Co. Inc., Woburn, MA). A flow rate of $1.0 \mathrm{ml} / \mathrm{min}$ was used with two solvents (A and B) set at 35\% B for 0-9 min, 55\% B for 10-35 min, and $85 \%$ B for 36-43 min where A was water/acetic acid (100:0.01 vol/vol) and $B$ was acetonitrile/acetic acid (100:0.01 vol/vol).

Selected compounds in the reverse-phase HPLC eluate were analyzed by straight-phase HPLC after extraction from the chromatographic solvent and conversion to methyl esters with ethereal diazomethane and methanol. Straight-phase HPLC was carried out using a guard cartridge and a $4.6 \times 100-\mathrm{mm}$ column packed with $3 \mu \mathrm{m}$ silanol-coated particles (Dynamax; Rainin Instrument Co., Inc.) at a flow rate of $2 \mathrm{ml} / \mathrm{min}$. Two solvents ( $A$ and $B$ ) were used in a program of 5\% B for 0-17 min, $10 \%$ B for $18-25 \mathrm{~min}, 45 \%$ B for $26-41 \mathrm{~min}$, and $80 \%$ B for $42-56$ min where A was hexane and B was hexane/2-propanol (100:8 vol/vol).

Compounds purified by straight-phase HPLC eluate were in turn analyzed by chiral-phase HPLC to determine absolute stereochemistry. Chiral-phase HPLC was performed with a pair of $4.6 \times 250-\mathrm{mm}$ columns in series which were packed with $5 \mu \mathrm{M}$ aminopropyl silica particles ionically bonded to dinitrobenzoylphenylglycine (J. T. Baker Chemical Co., Philipsburg, NJ) at a flow rate of $0.8 \mathrm{ml} / \mathrm{min}$. Two solvents (A and B) were used in an isocratic program of $8 \%$ B where $A$ was hexane and B was hexane/2-propanol (100:4 vol/vol).

Product detection. The HPLC eluate was monitored using a diode array spectrophotometer (model 1040; Hewlett-Packard Co.) set at 270 $\mathrm{nm}$ for conjugated triene diols (leukotrienes and diHETEs), $235 \mathrm{~nm}$ for conjugated dienes (HETEs and HODEs), and $193 \mathrm{~nm}$ for unconjugated double bonds (EETs and PGs). The outflow from the spectrophotometer was routed to a Flo-One-beta detector (Radiomatic Instruments \& Chemical Co., Inc., Tampa, FL) for concurrent measurement of ${ }^{3} \mathrm{H}$ or ${ }^{14} \mathrm{C}$. Standard molar absorption coefficients were used for quantification and verified by measurements based on specific activity as described previously (16).

Preparation of heavy isotope-labeled standards. The compound $\left[{ }^{18} \mathrm{O}_{2}\right] 12 S$-HETE was prepared from $\mathrm{H}_{2}{ }^{18} \mathrm{O}$ (MSD Isotopes, Montreal, Quebec, Canada) and unlabeled 12-HETE using type XI butyrylcholinesterase (Sigma Chemical Co.) as described previously (17). $\left[{ }^{2} \mathrm{H}_{8}\right] \mathrm{AA}$ was prepared from $(5,8,11,14)$-eicosatetraynoic acid (from J. Hamilton, Hoffman-La Roche, Nutley, NJ) and deuterium gas (MG Scientific Gases, North Branch, NJ) as described previously (18). $\left[{ }^{2} \mathrm{H}_{8}\right] 12-$ HETE was prepared from $\left[{ }^{2} \mathrm{H}_{8}\right]$ AA via the corresponding hydroperoxide by oxidation with $\mathrm{H}_{2} \mathrm{O}_{2}$ and $\mathrm{CuCl}_{2}$ followed by reduction with $\mathrm{NaBH}_{4}$ and then was purified by sequential reverse-phase and straight-phase HPLC as described previously (19-21). 


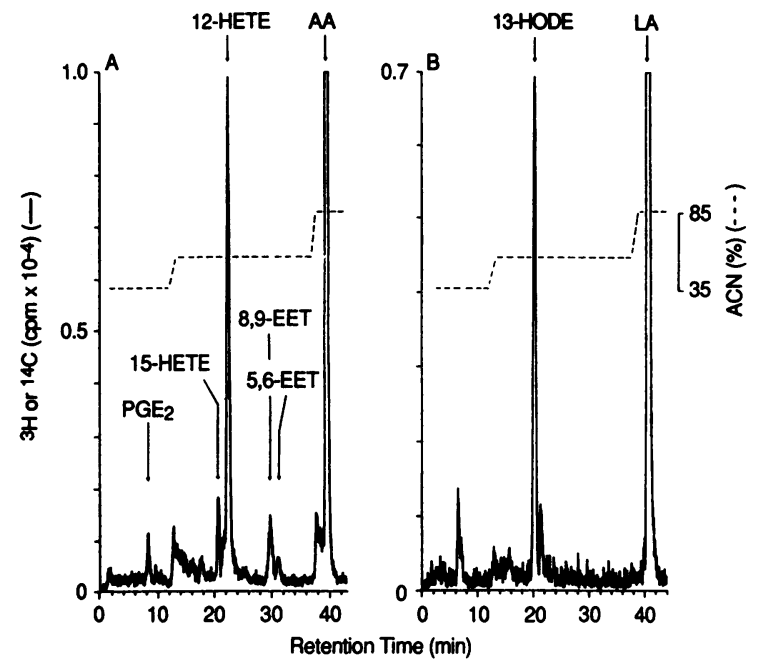

Figure 1. Analysis by reverse-phase HPLC of radiolabeled products released from epidermal cells incubated with $\mathrm{AA}(A)$ or linoleic acid (B). Aliquots of $4 \mathrm{ml}$ of $2.5 \times 10^{6} \mathrm{cells} / \mathrm{ml}$ in Hepes-buffered HBSS were incubated with $10 \mu \mathrm{M}\left[{ }^{3} \mathrm{H}\right] \mathrm{AA}$ or $\left[{ }^{14} \mathrm{C}\right]$ linoleic acid $\left(2 \times 10^{6}\right.$ $\mathrm{dpm} / \mathrm{ml}$ ) for $15 \mathrm{~min}$ at $37^{\circ} \mathrm{C}$. Products were extracted from cell supernatants into chloroform and resolved using the acetonitrile/water/ acetic acid system described in Methods. Major peaks of radioactivity coeluted with 12-HETE, AA, 13-HODE, and linoleic acid $(L A)$. Smaller peaks of activity corresponded to $\mathrm{PGE}_{2}, 15$-HETE, and 8,9and 5,6-EET.

Product derivatization. Carboxyl groups were converted to (a) methyl esters with ethereal diazomethane or $(b)$ pentafluorobenzyl esters (PFBE) by treatment with $N, N$-dimethylacetamide/tetramethylammonium hydroxide/methanol (8:5:15) and pentafluorobenzyl bromide/dimethylacetamide $(1: 3)$ for $30 \mathrm{~min}$ at room temperature, followed by concentration to dryness under $\mathrm{N}_{2}$, reconstitution in $\mathrm{H}_{2} \mathrm{O}$, and extraction with methylene chloride. Hydroxyl groups were converted to trimethylsilyl ether (TMSE) derivatives with $N, O$-bis(trimethylsilyl)trifluoroacetamide in pyridine for $30 \mathrm{~min}$ at room temperature.

Gas chromatography-mass spectrometry (GC-MS). Derivatives were analyzed on a gas chromatograph (model 5840A; Hewlett-Packard Co.) interfaced with a mass spectrometer (model 5985B; Hewlett-
Packard Co.). Samples were introduced into the chromatograph via a Grob-type injector operated in the splitless mode with helium as the carrier gas $\left(4 \mathrm{lb} / \mathrm{in}^{2}\right.$; injector temperature $\left.225^{\circ} \mathrm{C}\right)$ and analyzed on an 8 $\mathrm{m} \times 0.31 \mathrm{~mm}$, crosslinked methylsilicone capillary GC column (Ultraperformance; Hewlett-Packard Co.). GC oven temperature was programmed from 85 to $215^{\circ} \mathrm{C}$ at $30^{\circ} \mathrm{C} / \mathrm{min}$ starting $0.5 \mathrm{~min}$ after injection and then held at $215^{\circ} \mathrm{C}$. The mass spectrometer was operated either in the electron impact (EI) mode (ionization voltage $70 \mathrm{eV}$; source temperature $200^{\circ} \mathrm{C}$ ) or in the negative-ion chemical ionization (NICI) mode (ionization voltage $230 \mathrm{eV}$; source temperature $100^{\circ} \mathrm{C}$ ) with methane (source pressure 1 torr) as reagent gas. The genesis of selected ions (mass/charge; $\mathrm{m} / \mathrm{z}$ ) in the EI mass spectrum of the methyl ester, TMSE derivative of 12-HETE are $295\left\{\mathrm{M}-\left[\mathrm{CH}_{2}-\right.\right.$ $\left.\left.(\mathrm{CH})_{2}\left(\mathrm{CH}_{2}\right)_{6} \mathrm{CH}_{3}\right]\right\}$ and $173\left\{295\right.$-[TMSOH and $\left.\left.\mathrm{CH}_{3} \mathrm{OH}\right]\right\}$. The analogous ions in the mass spectrum of the methyl ester, TMSE derivative of $\left[{ }^{2} \mathrm{H}_{8}\right] 12$-HETE are 301 and $178(21)$. The major ion in the methane NICI mass spectrum of the PFBE, TMSE derivative of 12-HETE is 391 (M-181) generated by the loss of the pentafluorobenzyl moiety to yield a stable carboxylate anion $(21,22)$. The analogous ions in the methane NICI mass spectra of the PFBE, TMSE derivatives of $\left[{ }^{2} \mathrm{H}_{8}\right] 12-\mathrm{HETE}$ and of $\left[{ }^{18} \mathrm{O}_{2}\right] 12$-HETE are 399 and 395 , respectively $(21,22)$.

\section{Results}

Identification of cell products. Extracts of the media taken from suspensions of epidermal cells incubated with AA $(0.3-150 \mu \mathrm{M})$ invariably contained a compound comigrating with 12-HETE during analysis by reverse-phase HPLC (Fig. 1 $A$ ). Parallel experiments demonstrated that the cells converted linoleic acid predominantly to a compound with chromatographic properties and the ultraviolet (UV) absorption spectra of 13-HODE (Fig. $1 \mathrm{~B}$ ). Analysis of the peak corresponding to 12-HETE by repetitive UV scanning during reverse-phase HPLC and during straight-phase HPLC of the corresponding methyl ester indicated that the peak represented a single compound containing a conjugated diene structure. Confirmation of structure for the compound in the peak was provided by capillary-column GC and both positive-ion electron impact and negative-ion chemical ionization MS. In both ionization modes the epidermal cell-derived product yielded informative ions representing fragmentation patterns also observed with synthetic octadeuterated standards of 12-HETE (Figs. 2 and 3) and with ${ }^{18} \mathrm{O}_{2}$-labeled 12-HETE (not shown; 21, 22).
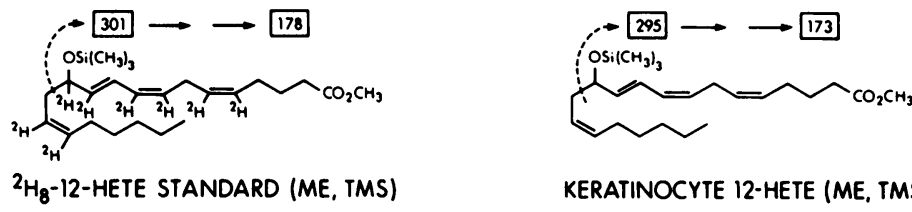

${ }^{2} \mathrm{H}_{8}$-12-HETE STANDARD (ME, TMS)

KERATINOCYTE 12-HETE (ME, TMS)
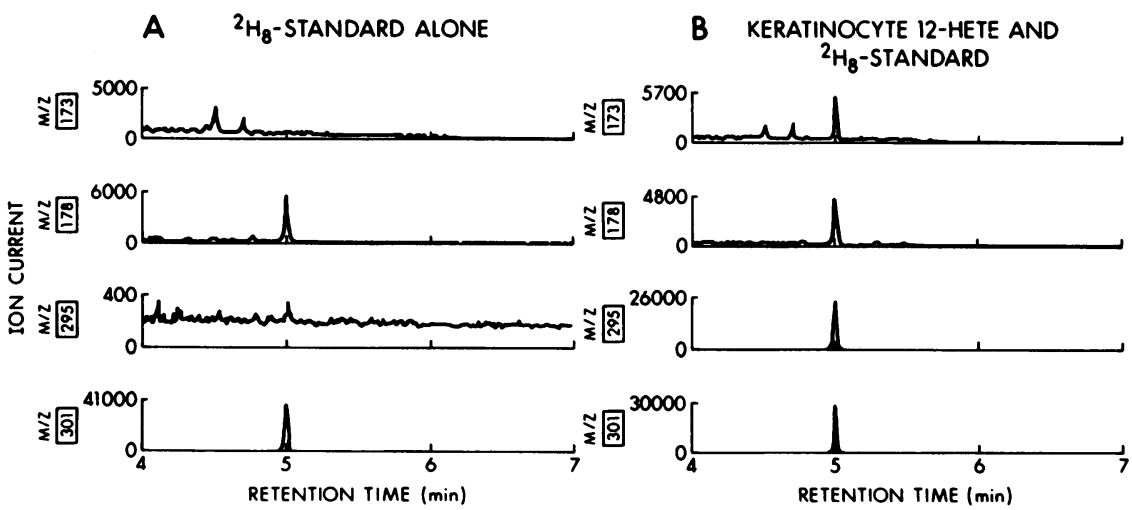

Figure 2. Analysis of 12-HETE released from epidermal cells by capillary column GC and positive-ion electron impact MS. Cells were incubated as described in Fig. 1, extracts of cell supernatants were subjected to reversephase HPLC, and the peak corresponding to 12-HETE was collected, converted to the methyl ester, rechromatographed on straightphase HPLC, and collected and converted to the corresponding TMSE derivative. The material and the corresponding octadeuterated standard were then analyzed by capillary column GC and positive-ion electron impact MS as described in Methods with selected monitoring of the ions $\mathrm{m} / \mathrm{z} 173$ and 295 for authentic 12-HETE and $\mathrm{m} / \mathrm{z} 178$ and 301 for the ${ }^{2} \mathrm{H}_{8}$-labeled internal standard. 


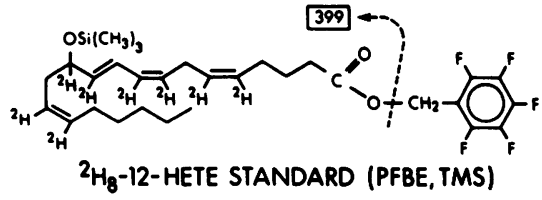

A ${ }^{2} \mathrm{H}_{8}$-STANDARD ALONE

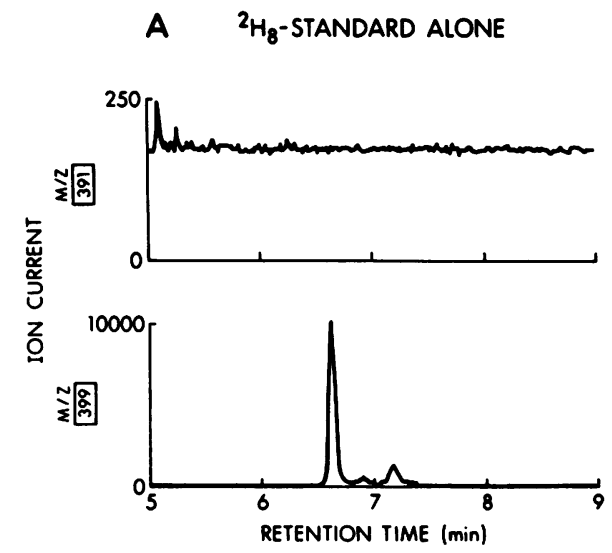

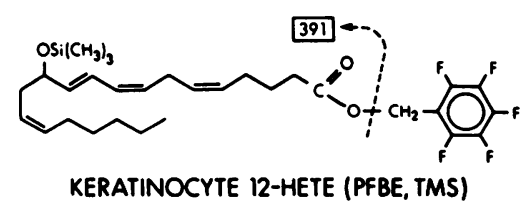

B KERATINOCYTE 12-HETE AND ${ }_{2} \mathrm{H}_{8}$-STANDARD
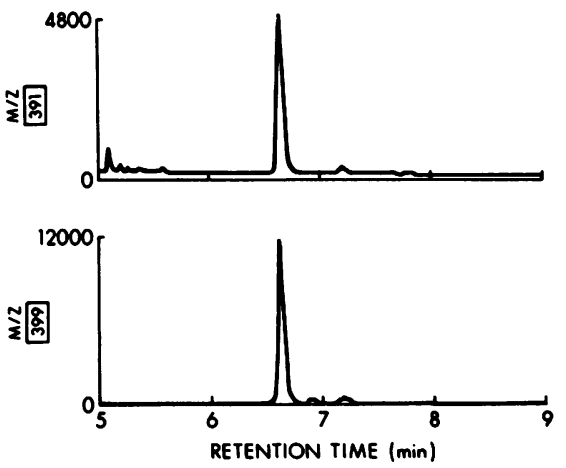

Figure 3. Analysis of 12-HETE derived from epidermal cells by capillary column GC and negative-ion chemical ionization MS. Extracts of cell supernatants prepared as in Fig. 1 were subjected to reverse-phase HPLC and the eluate corresponding to 12HETE was collected, converted to the PFBE, reanalyzed by reverse-phase HPLC, extracted from the reverse-phase HPLC solvent, and converted to the TMSE derivative. This material was then analyzed by capillary column GC and methane chemical ionization MS as described in Methods with monitoring of ions $\mathrm{m} / \mathrm{z} 391$ for authentic 12-HETE and $\mathrm{m} / \mathrm{z} 399$ for the ${ }^{2} \mathrm{H}_{8}$ labeled internal standard.
Other arachidonate metabolites recovered from cell incubations included 15-HETE identified by EI MS (not shown; 23) as well as lower levels of other compounds that were characterized by reverse-phase HPLC and UV absorption spectra (Table I). Two of these compounds exhibited the chromatographic and spectral characteristics of 8,9-EET and of 5,6EET. Production of these two compounds by epidermal cells suggested that these cells contained a monooxygenase that acted on AA $(12,24)$.

Several characteristics of 12-HETE formation from intact epidermal cells were determined and compared with the generation of the predominant cyclooxygenase product $\mathrm{PGE}_{2}$. Time

Table I. AA Products from Epidermal Cells

\begin{tabular}{|c|c|c|}
\hline $\begin{array}{l}\text { Retention } \\
\text { time* }\end{array}$ & Compound & Quantity \\
\hline $\min$ & & pmol/ $/ 10^{6} \mathrm{cells}^{\ddagger}$ \\
\hline 7.0 & $\mathrm{PGF}_{2 \alpha}$ & $14 \pm 7$ \\
\hline 8.3 & $\mathrm{PGE}_{2}$ & $104 \pm 37$ \\
\hline 9.7 & $\mathrm{PGD}_{2}$ & $13 \pm 4$ \\
\hline 21.2 & 15(S)-HETE & $22 \pm 8$ \\
\hline 21.2 & 15(R)-HETE & $5 \pm 2$ \\
\hline 23.0 & 12(S)-HETE & $105 \pm 17$ \\
\hline 23.0 & 12(R)-HETE & $21 \pm 4$ \\
\hline 24.4 & 5-HETE & n.d. ${ }^{\S}$ \\
\hline 33.4 & 8,9-EET & $20 \pm 9$ \\
\hline 34.4 & 5,6-EET & $8 \pm 6$ \\
\hline
\end{tabular}

* Epidermal cells were incubated with $20 \mu \mathrm{M}\left[{ }^{14} \mathrm{C}\right] \mathrm{AA}$ for $15 \mathrm{~min}$ at $37^{\circ} \mathrm{C}$ as described in Fig. 1, and products in the cell supernatant were separated by reverse-phase HPLC using the solvent program of acetonitrile/water/acetic acid.

${ }^{\ddagger}$ Quantities were determined by ultraviolet absorbance and specific activity. Values represent mean \pm SE for five experiments.

${ }^{\S}$ Not detected implies levels lower than $5 \mathrm{pmol} / 10^{6}$ cells and were also below this level for 8-, 9-, and 11-HETE. course of compound generation determined at several concentrations of AA showed that formation of both 12-HETE and $\mathrm{PGE}_{2}$ was $80-90 \%$ complete within $15 \mathrm{~min}$ at $37^{\circ} \mathrm{C}$. AA concentration-response curves showed that levels of both products were maximal at $10 \mu \mathrm{M}$ and half-maximal at $2 \mu \mathrm{M}$ substrate at $15 \mathrm{~min}$ at $37^{\circ} \mathrm{C}$ (Fig. 4). In addition, epidermal cells exhibited substrate inhibition of 12-HETE formation at concentrations of AA> $40 \mu \mathrm{M}$.

The stereochemistry of the epidermal cell 12-HETE was determined to gain further insight into its mechanism of formation. Absolute stereochemistry was assigned by coelution of epidermal cell-derived 12-HETE (that had been purified by sequential reverse- and then straight-phase HPLC) with authentic, stereochemically pure 12-HETE enantiomeric standards during chiral-phase HPLC. The 12-HETE generated by epidermal cells was found to consist predominantly but not exclusively of the $12 S$ isomer. Direct analysis of epidermal cell products by chiral-phase HPLC without previous HPLC purification yielded identical results (Fig. 5). Preparations from different subjects varied in the degree of stereospecific predominance, the molar ratio of $12 S / 12 R$-HETE averaging 5:1 (range 2:1-8:1) among preparations $(n=7)$. Because of the mixture of isomers, in particular the enzymatic formation of

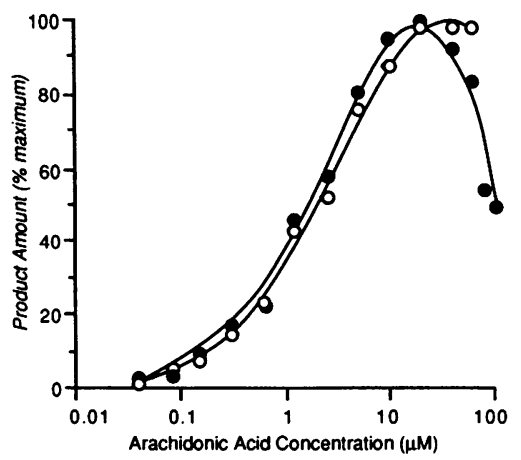

Figure 4. Arachidonate concentration-response for 12-HETE (•) and $\mathrm{PGE}_{2}(\mathrm{O})$ released from epidermal cells. Cell suspensions were prepared, incubated with AA for $15 \mathrm{~min}$ at $37^{\circ} \mathrm{C}$, and products extracted and resolved as described in Fig. 1. Each point represents the mean for two experiments in duplicate. 


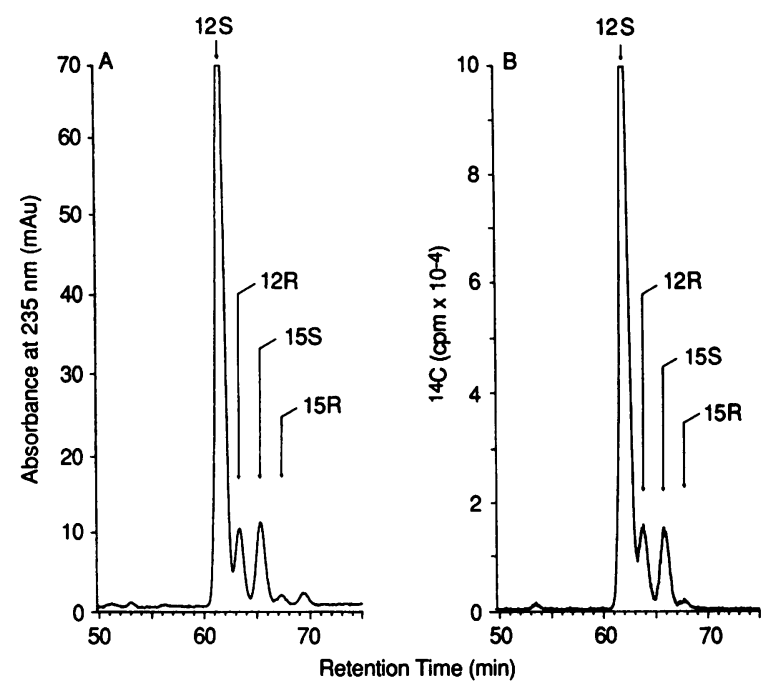

Figure 5. Analysis by chiral-phase HPLC of UV-active $(A)$ and radiolabeled $(B)$ arachidonate products released from epidermal cells. Epidermal cells were incubated with $10 \mu \mathrm{M}\left[{ }^{14} \mathrm{C}\right] \mathrm{AA}$ for $30 \mathrm{~min}$ at $37^{\circ} \mathrm{C}$ and products were converted to corresponding methyl esters and analyzed by HPLC using the hexane/2-propanol solvent system described in Methods.

$12 R$-HETE, we further suspected that the product might be derived at least in part via the activity of a monooxygenase $(10,25)$.

Subcellular fractionation. Initial experiments (not shown) confirmed that the arachidonate 12-lipoxygenase from bovine epithelial cells generated exclusively $12 S$-HETE and was confined to the $100,000 \mathrm{~g}$ supernatant ( $>90 \%$ of total activity), consistent with its characterization as a soluble cytoplasmic

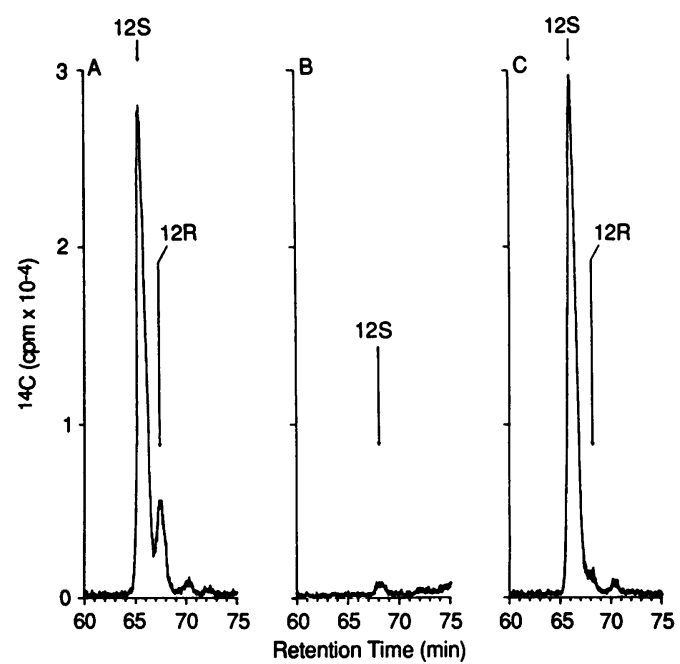

Figure 6. Chiral-phase HPLC analysis of the arachidonate products of $12,000 \mathrm{~g}$ pellet $(A), 100,000 \mathrm{~g}$ supernatant $(B)$, and $100,000 \mathrm{~g}$ pellet $(C)$ fractions from sonicated epidermal cells. Aliquots of 1-2 $\times 10^{8}$ cells $/ \mathrm{ml}$ were sonicated, subjected to differential centrifugation, and the resulting fractions incubated in $50 \mathrm{mM}$ Tris- $\mathrm{HCl}$ with 1 mM EDTA, $1 \mathrm{mM}$ EGTA, 5\% glycerol, $20 \mu \mathrm{M}\left[{ }^{14} \mathrm{C}\right] \mathrm{AA}, 1 \mathrm{mM}$ NADPH, and a G-6-P/G-6-PD regenerating system for $30 \mathrm{~min}$ at $37^{\circ} \mathrm{C}$ (total incubation vol of $2 \mathrm{ml}$ ). Products were extracted into diethylether and analyzed as described in Fig. 5.
Table II. Subcellular Fractionation of Epidermal Cell Oxygenation Activity

\begin{tabular}{lrrcr}
\hline \multicolumn{1}{c}{ Fraction* $^{*}$} & Activity & Protein & Sp act & $12 S / 12 R$ \\
\hline & $p m o l / m l^{\ddagger}$ & $\mu g / m l$ & $p m o l / \mu g$ protein & \\
Sonicate & 395 & 550 & 0.72 & 5 \\
$12,000 \mathrm{~g}$ pellet & 772 & 486 & 1.59 & 5 \\
$100,000 \mathrm{~g}$ supernatant & 36 & 3,145 & 0.01 & - \\
$100,000 \mathrm{~g}$ pellet & 858 & 525 & 1.63 & 16
\end{tabular}

* Assays carried out as described in Fig. 6.

¥ Values are derived from HPLC measurement of 12-HETE and represent mean for four experiments in duplicate.

enzyme $(13,14)$. By contrast, analysis of epidermal cell subcellular fractions demonstrated that all of the enzymatic capacity to generate 12-HETE was contained in the mitochondria$(12,000 \mathrm{~g}$ pellet) and microsome-enriched $(100,000 \mathrm{~g}$ pellet $)$ fractions (Fig. 6). Comparison between intact cell-, mitochondrial-, and microsome-derived 12-HETE subjected to analysis by chiral-phase HPLC showed that the molar ratio of $12 S / R$ HETE was increased up to $16: 1$ in the microsomal fraction (Table II).

Effects of pyridine nucleotides and carbon monoxide. Further characterization of the epidermal cell mitochondrial and microsomal oxygenation activity was carried out to determine the influence of exogenous NADPH and NADP/NAD competition. In both subcellular fractions activity was stimulated twofold by addition of an NADPH-generating system (Table III), while exogenous NADP/NAD did not significantly alter total 12-HETE formation.

Incubation of the epidermal cell 12,000 and $100,000 \mathrm{~g}$ fractions with carbon monoxide-containing buffer (molar ratio of carbon monoxide to oxygen, 7:1) resulted in means of 76-78\% inhibition in both mitochondrial and microsomal fractions (Table III). Comparative incubations with nitrogen caused no significant inhibition of activity (not shown). Susceptibility to inhibition by carbon monoxide is characteristic of a cytochrome P-450 monooxygenase (11,24). Incubation of bovine epithelial 12-lipoxygenase with carbon monoxide or

Table III. Modulation of Epidermal Cell Oxygenation Activity

\begin{tabular}{ccc}
\hline Fraction* & Sp act & $12 S / 12 R$ \\
\hline & $\%$ Maximum & \\
$12,000 \mathrm{~g}$ pellet & $58 \pm 6$ & 4 \\
+NADPH & 100 & 5 \\
+NADPH/CO & $24 \pm 2$ & -14 \\
100,000 $\mathrm{g}$ pellet & $49 \pm 5$ & 14 \\
+NADPH & 100 & 15 \\
+NADPH/CO & $22 \pm 4$ & $-"$
\end{tabular}

* The capacity of each fraction to generate 12-HETE was determined as described in Fig. 6.

‡ Values represent mean for three experiments.

${ }^{8}$ Carbon monoxide to oxygen molar ratio was $7: 1$.

"Levels of $12 R$-HETE were too low to determine accurate molar ratios. 
nitrogen caused no loss of activity for 12-HETE generation by either gas (not shown).

\section{Discussion}

The present data demonstrate that isolated human epidermal cells have the capacity to selectively convert AA to 12-HETE via the activity of a novel membrane-bound monooxygenase that is NADPH sensitive. This or an associated activity also converts AA to smaller amounts of 15-HETE and is capable of using linoleic acid as a substrate to form the 13-hydroxylated derivative (13-HODE). The pathway represents the major arachidonate oxygenation mechanism in epidermal cells with total product formation generally exceeding cyclooxygenase activity in these cells.

The evidence that arachidonate and linoleate hydroxylation is due to the activity of a monooxygenase rather than a lipoxygenase in our experiments rests on the following evidence: (a) the activity is localized to the 12,000 and $100,000 \mathrm{~g}$ pellets obtained from disrupted cells and therefore appears to be confined to mitochondria- and microsome-enriched fractions, a distribution that fits with the general rule that lipoxygenases are partially or completely soluble enzymes and monooxygenases are not (reviewed in reference 25); $(b)$ the epidermal cell 12-HETE-forming activity is enhanced by the addition of NADPH in comparison with controls; $(c)$ the activity is decreased by incubation with carbon monoxide-containing buffers; $(d)$ the human epidermal cells also generate a pair of epoxides (5,6- and 8,9-EETs), which reflects the action of a monooxygenase on AA; and (e) both intact cells and the mitochondrial and microsomal fractions generate some $12 R$ HETE, an enantiomer that is not known to be produced by mammalian 12-lipoxygenases but is produced by a P-450linked monooxygenase $(10,26)$.

Unusual features of the epidermal cell monooxygenation pathway include the regional specificity for 12-hydroxylation and the stereoselective predominance of the $12 S$ enantiomer. Previous reports of HETE generation from AA by hepatic and renal monooxygenases noted little regional specificity for enzyme-substrate interaction but definite stereochemical predominance of the $12 R$ over the $12 S$ isomer at least in rat liver microsomes (10). We found molar ratios of $12 S / 12 R$-HETE ranging from $2: 1$ to $18: 1$ depending on the subject and the type of enzyme preparation. Variation of $12 S / R$ ratios occurred among adult subjects so it is unlikely to be due to neonatal versus adult tissue or to regional heterogeneity in the skin. The ratio of $12 S / R$ was increased threefold in microsomal preparations relative to mitochondrial preparations. The mechanism for this alteration in the relative amounts of stereoisomers is uncertain, but the finding might suggest that two different enzymes (mitochondrial and microsomal) are responsible for the monooxygenase activity in epidermal cells. Relative increases in mitochondrial monooxygenase activity might therefore result in higher levels of $12 R$-HETE, while increases in microsomal activity would cause greater amounts of the $12 S$ isomer.

The predominance of the $12 S$ stereoisomer in epidermal 12-HETE might have reflected the existence of an arachidonate 12-lipoxygenase in these cells. To determine whether any of the epidermal HETE-forming activity was due to a lipoxygenase, we looked carefully for the generation of 12-lipoxy- genase-derived conjugated trienes (27), incubated cell products with a reducing agent to check for 12-hydroperoxide generation, and ran comparative experiments with identical procedures to check for destruction of a soluble tracheal epithelial cell 12-lipoxygenase activity. The lack of 12-series leukotriene or of 12-hydroperoxide formation by the epidermal cell preparation and the stability of tracheal epithelial cell 12-lipoxygenase activity to the conditions used to examine epidermal cell 12-HETE-forming activity all indicate that we did not fail to detect 12-lipoxygenase activity but rather that epidermal cells contain little or no 12-lipoxygenase activity. Because the absolute level of the $12 S$-isomer was increased by NADPH and decreased by carbon monoxide, it is likely that the epidermal $12 S$-HETE was derived via a monooxygenase.

Both the regiospecificity and the $12 S$ stereopreference of the epidermal enzyme(s) are novel features for a cytochrome P-450 monooxygenase that acts on AA. Another novel feature is the subcellular distribution of the epidermal cell monooxygenase system, and in particular its high specific activity in the mitochondria-enriched $12,000 \mathrm{~g}$ pellet from subcellular fractionation. Although absolute specificity of fractionation is not possible, the relatively high specific activity for 12-HETE formation in this fraction suggests that microsomal contamination is an unlikely source of the entire activity. In addition, the difference in the profile of stereoisomers in the two fractions suggests that two distinct enzyme systems may be expressed in epidermal cells. Although there is no precedent for monooxygenase activity resulting in AA oxygenation in mitochondria, mitochondrial P-450 type enzymes have been described that participate in the biosynthesis of steroid hormones and bile acids $(28,29)$.

Our results contrast with studies of keratinocytes cultured from humans. Cultured keratinocytes exhibited little evidence of 12-HETE generation in comparison with freshly isolated cells (30; and Holtzman, M. J., and A. Pentland, unpublished observations using neonatal and adult cells). One explanation for differences between freshly isolated and cultured cell oxygenation pathways is the loss of a subset of epidermal cells during culture. The vast majority of freshly isolated epidermal cells are keratinocytes, but Merkel cells, Langerhans cells, and melanocytes may also be present and may not survive in culture. Differences between cultured and freshly isolated cells might also be due to an alteration in the expression of keratinocyte oxygenation pathways during growth in artificial media. Support for this possibility comes from the finding that the ability of keratinocytes (and other epithelial cell types) to generate HETEs are markedly diminished during culture under a wide variety of conditions (31; and Holtzman, M. J., and A. Pentland, unpublished observations). Determination of factors that regulate the expression of oxygenase activity may help explain the basis for differences between freshly isolated and cultured cell arachidonate metabolism and enable better definition of the role of these enzymatic pathways in keratinocyte function.

Although products of keratinocyte cyclooxygenase activity may have a number of clearly established biologic actions (25), the biological function of products derived from the arachidonate monooxygenase pathway have been less clearly defined. Possibilities might include: $(a)$ the reaction consumes excess molecular oxygen or AA in the cell; $(b)$ the reaction changes cellular redox balance; and (c) 12-HETE and/or some 
other products of the reaction are specific biologically active mediators. Recently, potent effects of 12-HETE on vascular myocyte movement, endothelial cell growth, neuronal synaptic transmission, and $\mathrm{Na}^{+}, \mathrm{K}^{+}$-ATPase-mediated ion transport have been reported $(26,32-34)$. Of further interest is the augmented neutrophil chemotactic effect of $12 R$ compared with $12 S$-HETE $(35,36)$. The implications for these findings in epidermal function are currently under investigation, but it is intriguing that high levels of $12 R$-HETE are found in lesional psoriatic skin while high levels of $12 S$-HETE are formed by human epidermal cells from healthy skin. Whether the stereospecificity of the enzyme that is expressed in inflammatory skin disease is different from that in normal skin requires further investigation, but our results provide the initial evidence that the stereochemical composition of 12-HETE produced by keratinocytes may change under different conditions.

\section{Acknowledgments}

The authors gratefully thank Barbara Ferdman, W. Thomas Stump, Susan Jacobs, and My Mahoney for expert technical assistance. The authors also gratefully acknowledge the Washington University Mass Spectrometry Resource Center supported by Division of Research Resources grant RR-00954 from the National Institutes of Health (NIH).

This research was supported by grants HL-40078, DK-01553, DK-34388, HL-36409, AM-38111, and AR-01496 from the NIH. Dr. Holtzman is the Schering Career Investigator of the American Lung Association.

\section{References}

1. Hammarstrom, S., M. Hamberg, B. Samuelsson, E. A. Duell, M. Stawiski, and J. J. Voorhees. 1975. Increased concentrations of nonesterified arachidonic acid, 12L-hydroxy-5,8,10,14-eicosatetraenoic acid, prostaglandin $\mathrm{E}_{2}$, and prostaglandin $\mathrm{F}_{2 \alpha}$ in epidermis of psoriasis. Proc. Natl. Acad. Sci. USA. 72:5130-5134.

2. Brain, S., R. Camp, P. Dowd, A. Kobza Black, and M. Greaves. 1984. The release of leukotriene $B_{4}$-like material in biologically active amounts from the lesional skin of patients with psoriasis. J. Invest. Dermatol. 83:70-73.

3. Camp, R. D. R., A. I. Mallet, P. M. Woollard, S. D. Brain, A. Kobza Black, and M. W. Greaves. 1983. The identification of hydroxy fatty acids in psoriatic skin. Prostaglandins. 26:431-447.

4. Duell, E. A., C. N. Ellis, and J. J. Voorhees. 1988. Determination of 5,12, and 15-lipoxygenase products in keratomed biopsies of normal and psoriatic skin. J. Invest. Dermatol. 91:446-450.

5. Hammarstrom, S., J. A. Lindgren, C. Marcelo, E. A. Duell, T. F. Anderson, and J. J. Voorhees. 1979. Arachidonic acid transformations in normal and psoriatic skin. J. Invest. Dermatol. 73:180-183.

6. Ziboh, V. A., T. L. Casebolt, C. L. Marcelo, and J. J. Voorhees. 1984. Biosynthesis of lipoxygenase products by enzyme preparations from normal and psoriatic skin. J. Invest. Dermatol. 83:426-430.

7. Chan, C.-C., L. Duhamel, and A. Ford-Hutchison. 1985. Leukotriene $B_{4}$ and 12-hydroxyeicosatetraenoic acid stimulate epidermal proliferation in vivo in the guinea pig. J. Invest. Dermatol. 85:333334.

8. Soter, N. A., R. A. Lewis, E. J. Corey, and K. F. Austen. 1983. Local effects of synthetic leukotrienes $\left(\mathrm{LTC}_{4}, \mathrm{LTD}_{4}, \mathrm{LTE}_{4}\right.$, and $\left.\mathrm{LTB}_{4}\right)$ in human skin. J. Invest. Dermatol. 80:115-119.

9. Woollard, P. M. 1986. Stereochemical difference between 12hydroxy-5,8,10,14-eicosatetraenoic acid in platelets and psoriatic lesions. Biochem. Biophys. Res. Commun. 136:169-176.

10. Capdevila, J., P. Yadagiri, S. Manna, and J. R. Falck. 1986. Absolute configuration of the hydroxyeicosatetraenoic acids (HETEs) formed during catalytic oxygenation of arachidonic acid by micro- somal cytochrome P-450. Biochem. Biophys. Res. Commun. 141:1007-1011.

11. Oliw, E. H., J. A. Lawson, A. R. Brash, and J. A. Oates. 1981. Arachidonic acid metabolism in rabbit renal cortex. J. Biol. Chem. 256:9924-9931.

12. Laniado-Schwartzman, M., K. L. Davis, J. C. McGiff, R. D. Levere, and N. G. Abraham. 1988. Purification and characterization of cytochrome P-450-dependent arachidonic acid epoxygenase from human liver. J. Biol. Chem. 263:2536-2542.

13. Hansbrough, J. R., A. B. Atlas, J. Turk, and M. J. Holtzman. 1989. Arachidonate 12-lipoxygenase and cyclooxygenase:PGE isomerase are predominant pathways for oxygenation in bovine tracheal epithelial cells. Am. J. Respir. Cell Mol. Biol. In press.

14. Hansbrough, J. R., A. B. Atlas, J. Turk, Y. Takahashi, N. Ueda, S. Yamamoto, and M. J. Holtzman. 1989. Identification and characterization of an arachidonate 12-lipoxygenase in bovine tracheal epithelial cells. Clin. Res. 37:476A. (Abstr.)

15. Hunter, J. A., W. E. Finkbeiner, J. A. Nadel, E. J. Goetzl, and M. J. Holtzman. 1985. Predominant generation of 15-lipoxygenase metabolites of arachidonic acid by epithelial cells from human trachea. Proc. Natl. Acad. Sci. USA. 82:4633-4637.

16. Holtzman, M. J., J. R. Hansbrough, G. D. Rosen, and J. Turk. 1988. Uptake, release, and novel species-dependent oxygenation of arachidonic acid in human and animal airway epithelial cells. Biochim. Biophys. Acta. 963:401-413.

17. Westcott, J. Y., K. L. Clay, and R. C. Murphy. 1985. Preparation of oxygen-18-labeled lipoxygenase metabolites of arachidonic acid. Biomed. Mass Spectrom. 12:714-718.

18. Taber, D. F., M. A. Phillips, and W. C. Hubbard. 1981. Preparation of deuterated arachidonic acid. Prostaglandins. 22:349-353.

19. Boeynaems, J. M., J. A. Oates, and W. C. Hubbard. 1980. Preparation and characterization of hydroperoxy-eicosatetraenoic acids (HPETEs). Prostaglandins. 19:87-97.

20. Boeynaems, J. M., A. R. Brash, J. A. Oates, and W. C. Hubbard. 1980. Preparation and characterization of monohydroxy-eicosatetraenoic acids. Anal. Biochem. 104:259-267.

21. Turk, J., J. R. Colca, N. Kotagal, and M. L. McDaniel. 1984. Arachidonic acid metabolism in isolated pancreatic islets. I. Identifcation and quantitation of lipoxygenase and cyclooxygenase products. Biochim. Biophys. Acta. 794:110-124.

22. Turk, J., B. A. Wolf, R. A. Easom, J. H. Hughes, and M. L. McDaniel. 1989. Arachidonic acid metabolism in isolated pancreatic islets. V. The enantiomeric composition of 12-hydroxy-5,8,10,14-eicosatetraenoic acid indicates synthesis by a 12-lipoxygenase rather than a monooxygenase. Biochim. Biophys. Acta. 1001:16-24.

23. Turk, J., R. L. Maas, A. R. Brash, L. J. Roberts, and J. A. Oates. 1982. Arachidonic acid 15-lipoxygenase products from human eosinophils. J. Biol. Chem. 257:7068-7076.

24. Oliw, E. H., F. P. Guengerich, and J. A. Oates. 1982. Oxygenation of arachidonic acid by hepatic monooxygenases. Isolation and metabolism of four epoxide intermediates. J. Biol. Chem. 257:37713781.

25. Holtzman, M. J. 1990. Sources of inflammatory mediators in the lung: the role of epithelial and leukocyte pathways for arachidonic acid oxygenation. In Mediators of Pulmonary Inflammation, Lung Biology in Health and Disease. M. Bray, W. Anderson, and C. Lenfant, editors. Marcel Dekker, Inc., New York. In press.

26. Schwartzman, M. L., M. Balazy, J. Masferrer, N. G. Abraham, J. C. McGiff, and R. C. Murphy. 1987. 12(R)-Hydroxyicosatetraonoic acid: a cytochrome P450-dependent arachidonate metabolite that inhibits $\mathrm{Na}^{+}, \mathrm{K}^{+}$-ATPase in the cornea. Proc. Natl. Acad. Sci. USA. 84:8125-8129.

27. Takahashi, Y., N. Ueda, and S. Yamamoto. 1988. Two immunologically and catalytically distinct arachidonate 12-lipoxygenases of bovine platelets and leukocytes. Arch. Biochem. Biophys. 266:613621.

28. Canick, J. A., and K. J. Ryan. 1978. Properties of the aromatase 
system associated with the mitochondrial fraction of human placenta. Steroids. 32:499-509.

29. Andersson, S., D. L. Davis, H. Dahlback, H. Jornvall, and D. W. Russell. 1989. Cloning, structure, and expression of the mitochondrial cytochrome P-450 sterol 26-hydroxylase, a bile acid biosynthetic enzyme. J. Biol. Chem. 264:8222-8229.

30. Burrall, B. A., M. Cheung, A. Chiu, and E. J. Goetzl. 1988. Enzymatic properties of the 15-lipoxygenase of human cultured keratinocytes. J. Invest. Dermatol. 91:294-297.

31. Holtzman, M. J., A. Pentland, N. L. Baenziger, and J. R. Hansbrough. 1989. Heterogeneity of cellular expression of arachidonate 15-lipoxygenase: implications for biological activity. Biochim. Biophys. Acta. 1003:204-208.

32. Nakao, J., T. Ooyama, H. Ito, W.-C. Chang, and S. Murota. 1982. Comparative effect of lipoxygenase products of arachidonic acid on rat aortic smooth muscle cell migration. Atherosclerosis. 44:339342.
33. Setty, B. N. Y., J. E. Graeber, and M. J. Stuart. 1987. The mitogenic effect of 15- and 12-hydroxyeicosatetraenoic acid on endothelial cells may be mediated via diacylglycerol kinase inhibition. $J$. Biol. Chem. 262:17613-17622.

34. Piomelli, D., A. Volterra, N. Dale, S. A. Siegelbaum, E. R. Kandel, J. H. Schwartz, and F. Belardetti. 1987. Lipoxygenase metabolites of arachidonic acid as second messengers for presynaptic inhibition of Aplysia sensory cells. Nature (Lond.). 328:38-43.

35. Cunningham, F. M., and P. M. Woollard. 1987. 12(R)-Hydroxy-5,8,10,14-eicosatetraenoic acid is a chemoattractant for human polymorphonuclear leukocytes in vitro. Prostaglandins. 34:71-78.

36. Evans, J. F., Y. Leblanc, B. J. Fitzsimmons, S. Charleson, D. Nathaniel, and C. Leveille. 1987. Activation of leukocyte movement and displacement of $\left[{ }^{3} \mathrm{H}\right]$ leukotriene $\mathrm{B}_{4}$ from leukocyte membrane preparations by (12R)- and (12S)-hydroxyeicosatetraenoic acid. Biochim. Biophys. Acta. 917:406-410. 